COMMENTARY

\title{
Estimation Uncertainty and the IASB's Proposed Conceptual Framework
}

\author{
by \\ Russell Craig* \\ Wally Smieliauskas \\ Joel Amernic
}

\section{Summary at a Glance}

The IASB's proposed Conceptual Framework does not encourage better ways to report uncertainty and risk. It should be revised to

- create a CF that is the overarching authority for accounting standards;

- put bounds on estimation uncertainty;

- incorporate estimation uncertainty in the definition of assets and liabilities; and

- improve the auditability of reported accounting estimates.

JEL Codes: M 410, M 420

* Corresponding author

Russell Craig

Portsmouth Business School

Richmond Building

Portland Street

Portsmouth UK

Russell.Craig@port.ac.uk and Russell.Craig@vu.edu.au

+610478409619

\section{Brief Author Biography}

Russell Craig is Professor of Accounting, University of Portsmouth, UK. He is Honorary Adjunct Professor at Victoria University, Australia; and at the University of Canterbury, New Zealand. Wally Smieliauskas and Joel Amernic are Professors of Accounting at the Joseph L. Rotman School of Management, University of Toronto, Canada. 


\section{Estimation Uncertainty and the IASB's Proposed Conceptual Framework}

In December 2015, CPA Australia responded formally to the International Accounting Standards Board (IASB) proposing certain actions and priorities in respect of the IASB's agenda and work plan for 2016-2020. CPA Australia urged the IASB to give the completion of its Conceptual Framework $(\mathrm{CF})$ program the highest priority and to ensure that any ensuing $\mathrm{CF}$ incorporated 'robust concepts for financial reporting.'

This commentary reinforces and extends the CPA Australia response by highlighting four specific areas in which the IASB's current proposals for a CF (outlined in Conceptual Framework for Financial Reporting: Exposure Draft, May 2015) are inadequate and need to encourage better ways of reporting uncertainty and risk. We urge the IASB to address these matters so as to assist in developing better and 'more robust' financial reporting.

The IASB's exposure draft (ED) does not adequately consider the lack of auditability that influences how accounting estimates are reported. The ED does not put bounds on estimation uncertainty or suitably incorporate estimation uncertainty in its definition of assets and liabilities. Nor does it propose a CF that will become the overarching authority for financial reporting and lead to the development of accounting standards that will be conducive to deterring unethical reporting. By ethical reporting we mean truthful reporting - in the sense that an estimate is at least more likely to be achieved than not. With little regard for the truthfulness of an estimate, the role of an auditor is diminished. This is because the purpose of an audit is to enhance confidence in the financial reporting.

Below, we describe four ways in which the IASB's proposals for a CF could be improved and result in more consistent and ethical reporting.

\section{Failure to create a CF that is the overarching authority for accounting standards}

A fundamental problem with the $\mathrm{ED}$ is the status of the proposed $\mathrm{CF}$ relative to existing standards. The ED states that 'nothing in the CF overrides any specific existing standards' and that 'the IASB may sometimes specify requirements that depart from aspects of the CF' (paragraph IN2-3). Such a position deviates from a principles-based reasoning system. It creates 
opportunities for unethical and fraudulent reporting, especially when combined with concepts that condone risky and potentially unauditable accounting estimates.

International Standards on Auditing (ISA) have a more logical, and more structured approach to standard setting. They use a 'clarity format'. This comprises an introduction, purpose, concepts and definitions, requirements of the standard, application guidance, and other explanatory material, including contexts when a standard meets (and does not meet) its intended objective. This makes the intent of an audit standard much clearer. Application of such a format in accounting and financial reporting would require a $\mathrm{CF}$ to preclude departures from the objectives and foundations of the CF. This would emphasise the importance of reporting truthfully to users of financial statements.

The CF for auditing (comprising ISA 200 and ISA 210) does not permit any ISA to deviate from the fundamental purpose of an audit. However, no similar requirement for the $\mathrm{CF}$ of financial reporting is proposed in the IASB ED. This creates a crucial inconsistency between auditing and financial reporting.

The IASB CF should take precedence when conflicts arise with detailed accounting standards: for example, in meeting the needs for different users, such as existing and potential investors. If the goal of financial reporting is to contribute to well-functioning capital markets, then there is a paramount need for potential investors to be confident that they will not be exploited by existing investors (and management) through misleading reporting.

Auditing standards distinguish between fraud for a company and fraud against a company (ISA 240). Existing investors can have less concern for fraud that is in the firm's interest. However, potential investors should be much more concerned. Thus, to maintain consistent standard setting, the CF should specify a hierarchy of user needs. When user needs conflict it is important to be clear about whose interests prevail. Moreover, the ultimate objective of financial reporting should be truthfulness about the information being reported. This is because decision usefulness depends on truthful reporting.

\section{Failure to put bounds on estimation uncertainty}

Financial accounting would be improved considerably if core principles in the CF controlled the uncertainty in estimating assets and liabilities to acceptable and verifiable levels. A prime example is the new IFRS 9 on accounting for financial instruments, which the IASB 
acknowledges may result in unreliable valuation estimates. An acceptable level of uncertainty is one that does not result in significant risk of material misstatement. This level should be stated as the condition to be satisfied by the accounting numbers reported on the face of financial statements. The acceptability of levels of estimation uncertainty is a fundamental issue: it affects the truthfulness and ethicality of accounting estimates. Auditability of accounting estimates (in the sense of IFAC DP 2011) is the key to determining the truthfulness of estimates. However, there is no explicit requirement in the $\mathrm{CF}$ that the estimates, and any related disclosures in notes, should be auditable.

The IASB ED does not prevent management from recognising rare future events of high positive (or negative) consequence, and high estimation uncertainty. How such (relatively) rare future events are recognised and verified is a strong concern of the International Auditing and Assurance Standards Board (IAASB) (Project to Revise ISA 540, March 2016, accessible at http://www.ifac.org/publications-resources/isa-540-revision-project-publication). The reporting of future events in financial statements should be addressed at a fundamental level in the CF, and serve as a guide to more detailed standards.

\section{Failure to incorporate estimation uncertainty in the definition of assets and liabilities}

The IASB ED conception of assets (paragraphs BC 4.24-28; BC 5.39-40) will increase the risk of unethical and unauditable reporting. The IASB believes uncertainties associated with estimates should not be dealt with at a conceptual level (paragraph 5.45), but in accounting standards that address specific issues. The likelihood of a gap in the coverage of individual accounting standards points to the need for limits on estimation uncertainty to be incorporated into the basic concept of an asset. This is equivalent to saying that minimal conditions for truthfulness must be met before estimated assets would be reported as point estimates in financial statements.

\section{Failure to address a lack of auditability of reported accounting estimates}

If many accounting estimates are not auditable, as we believe, this ought to raise serious questions about the appropriateness of ensuing accounting numbers that are reported in financial statements prepared in conformity with the IASB ED. 
An IFAC Discussion Paper (The Evolving Nature of Financial Reporting: Disclosure and its Audit Implications, 2011) posed the following crucial question regarding accounting estimates. If the estimates allowed by the IASB do not result in auditable information, should such information be included in financial statements? This fundamental question should be addressed in the IASB's proposed CF.

Auditing standards must co-exist with a $\mathrm{CF}$ of financial reporting that acknowledges the importance of the auditability of accounting estimates. However, perversely, the IASB ED condones the reporting of accounting estimates that lack auditability. Estimates lacking auditability should not be included as numbers in the body of financial statements. Nevertheless, narrative information can be included in notes, provided the indications of uncertainty are appropriate and auditable. However, there is no explicit requirement in the CF that the note disclosures should be auditable. This is also a problem with IAASB (2016).

A key question in relation to the auditability of financial reporting disclosures is 'the extent to which management has documented supporting evidence' (IFAC DP 2011: paragraph 106). A summary of recent research sponsored by the PCAOB in a 2013 special issue of Auditing, A Journal of Practice and Theory indicates that such documentation is often calibrated poorly and is very subjective. Thus, it is questionable whether any disclosure by management of the range of possibilities associated with an estimate will be a good indicator of the risk involved. If the range is calibrated poorly or has only low assurance, this will render the estimate unauditable. If so, any associated disclosure in notes is likely to be unauditable too.

\section{Conclusion}

Further consideration by the IASB of the four matters raised above will help ensure that the CF becomes the overarching authority in financial reporting; that a principles-based reasoning system is implemented consistently, and that the CF will result in more truthful, and thus more ethical, reporting. Consideration of these matters will also help achieve CPA Australia's much sought-after 'robust concepts for financial reporting.' 